\title{
Carcinoma de células basais em periquito australiano (Melopsittacus undulatus): relato de caso
}

\section{Basal cell carcinoma in budgerigars (Melopsittacus undulatus): case report}

\author{
Andréa de Andrade Rangel de Freitas, ${ }^{*}$ Marcelo Guilherme Bezerra Levy, ${ }^{* *}$ Denise Monnerat Nogueira, ${ }^{* * *}$ \\ Flávia Liparisi, ${ }^{* * *}$ Rogério Tortelly ${ }^{* * * * *}$
}

\begin{abstract}
Resumo
As neoplasias do sistema tegumentar são relativamente comuns em aves de cativeiro. Os tumores localizados na derme, em aves de estimação, podem ser de origem epitelial e mesenquimal, sendo que os carcinomas de células basais parecem ser extremamente raros em aves. Um periquito macho adulto foi encaminhado a uma clínica particular apresentando uma massa tumoral na epiderme, e localizada na região medial do úmero direito. Optou-se pela amputação da asa afetada e o diagnóstico de carcinoma de células basais foi feito pela histopatologia.
\end{abstract}

Palavras-chave: carcinoma de células basais, oncologia, periquito australiano, Psittacidae.

\begin{abstract}
Tumors of the integumentary system are relatively common in captive birds. Dermal tumors in pet birds can be epithelial and mesenchymal in origin. Basal cells carcinomas appear seem to be extremely rare in birds. An adult male budgerigar was examined exhibiting a tumor mass situated at the epidermis and in the medial region of the right humerus. The wing was amputated and histopathology diagnosis identified basal cell carcinoma.
\end{abstract}

Keywords: basal cell carcinoma, oncology, budgerigars, Psittacidae.

\section{Introdução}

Neoplasias do sistema tegumentar são relativamente comuns em aves (Arnall, 1958; Reece, 1992). Em periquitos australianos (Melopsittacus undulatus) as neoplasias são enfermidades freqüentes (Baker, 1980). Em um laboratório de diagnóstico veterinário na Austrália, os periquitos australianos representaram $69,7 \%$ de todos os casos de neoplasias detectados em psitacídeos e $41 \%$ de todas as neoplasias encontradas em aves (Reece, 1992). Comparado às aves de vida livre, as neoplasias em aves de cativeiro são relatadas com maior freqüência (Baker, 1980; Reece, 1992). Segundo Latimer (1994) isto ocorre devido à maior expectativa de vida e ao contato próximo com seres humanos, o que facilita a detecção de anormalidades. Além disso, pode haver uma predisposição genética para o desenvolvimento de neoplasias devido aos acasalamentos consangüíneos (Munson, 1993; Latimer, 1994). Pouco se conhece, entretanto, a respeito da etiologia, fatores predisponentes, desenvolvimento, comportamento biológico e tratamento adequado das neoplasias em aves de companhia (Latimer, 1994). O presente trabalho descreve um caso de carcinoma de células basais em periquito australiano (Melopsittacus undulatus), localmente invasivo, na região medial da asa direita.

\section{Casuística}

Um periquito australiano (Melopsittacus undulatus) macho com oito anos de idade, pesando $30 \mathrm{~g}$ foi encaminhado a uma clínica particular na cidade do Rio de Janeiro, RJ, Brasil, para a avaliação de um aumento de volume na região umeral da asa direita. A ave era mantida sozinha em uma gaiola de ferro e alimentada com mistura de sementes. Não havia histórico de doença anterior e o período de início da lesão é desconhecido; entretanto, o proprietário relatou episódios sucessivos de ferimento com sangramento na asa. Ao exame físico, o paciente estava em boas condições de saúde, mas apresentava alteração na postura, mantendo a asa direita afastada do corpo e ligeiramente caída devido ao tamanho e peso das lesões. A massa principal localizada na região do úmero, na face medial da asa direita, possuía $2 \mathrm{~cm}$ de diâmetro com área central ulcerada, por onde havia perda de sangue. As penas eram ausentes em toda a área afetada e a pele apresentava aspecto espessado, coloração amarelada e

\footnotetext{
* Médica-veterinária autônoma. E-mail: andreaarfreitas@hotmail.com

** Médico-veterinário autônomo

*** Faculdade de Veterinária/MZO/UFF

**** Centro Universitário Plínio Leite

*****Faculdade de Veterinária/MPT/UFF
} 
consistência firme. A lesão mostrou-se localmente invasiva, estendendo-se até a região do metacarpo com múltiplos nódulos variando em diâmetro, mas com as mesmas características da massa principal. Para obtenção de uma margem cirúrgica adequada, sem evidência de células neoplásicas, optou-se pela completa amputação da asa direita na articulação escápulo-umeral.

O tecido tumoral extraído foi acondicionado em solução de formalina neutra a $10 \%$, processado pelas técnicas habituais para inclusão em parafina, seccionado e corado com hematoxilina e eosina. A análise microscópica revelou um processo neoplásico maligno, de origem epitelial, formado por mantos de células basalóides pleomórficas (Figura 1). 0 crescimento mostrou-se infiltrativo, comprometendo a musculatura adjacente, e o índice mitótico era elevado, inclusive com figuras anômalas. Os núcleos eram redondos a ovalados, hipercromáticos e com um ou dois nucléolos proeminentes (Figura 2). Além disso, foram encontrados focos de hemorragia, inflamação e necrose.

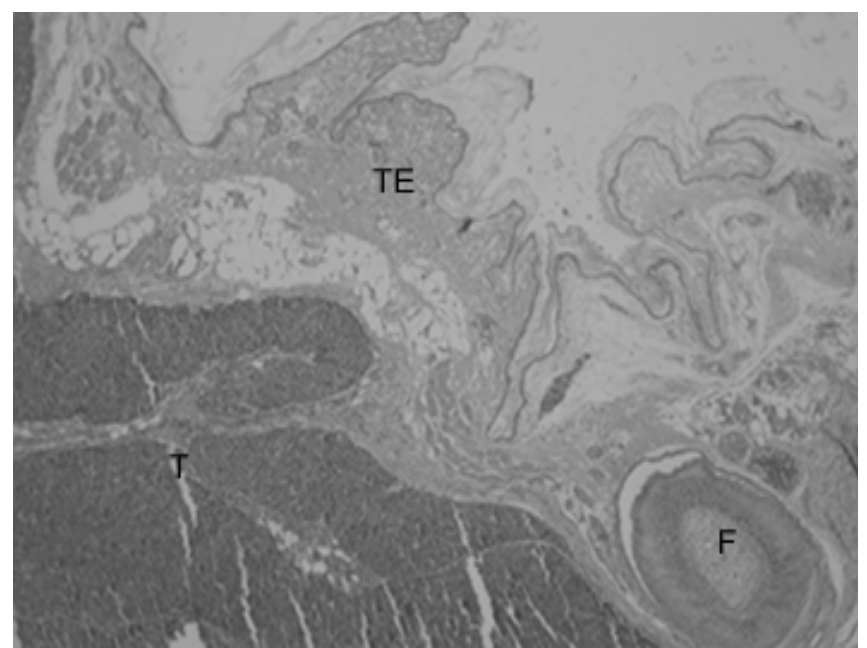

Figura 1: Melopsittacus undulatus. Carcinoma basocelular. Células basalóides dispostas em folhetos sólidos pela derme profunda. HE " 40X. T - Tumor, F - Folículo plumoso, TE - Tecido epitelial

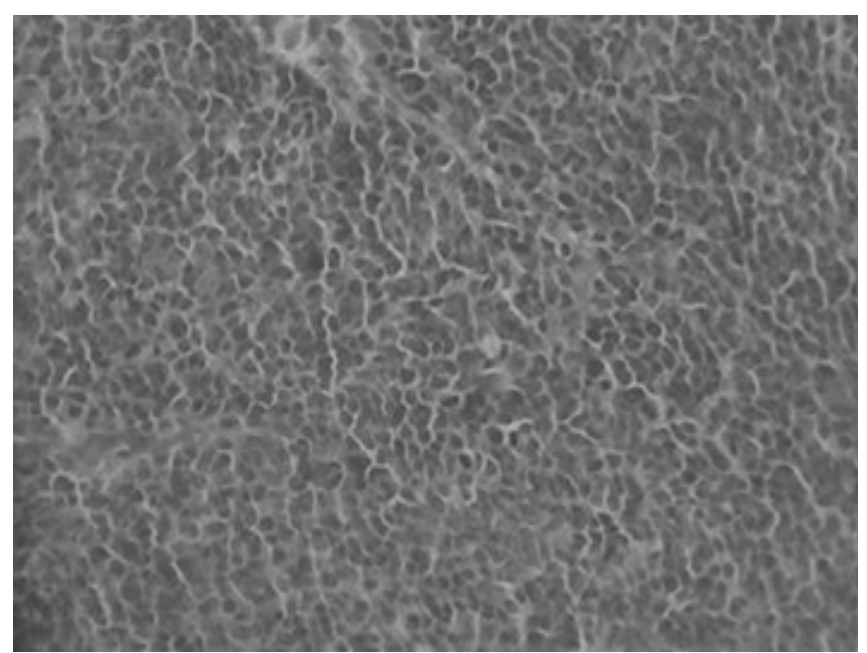

Figura 2 - Melopsittacus undulatus. Carcinoma basocelular. Detalhe da figura anterior. Notar o pleomorfismo celular, hipercromatismo nuclear e figuras de mitose das células neoplásicas. HE " 400X.

\section{Discussão e conclusão}

As alterações macroscópicas e histopatológicas neste caso estão de acordo com as encontradas nas três descrições de carcinoma de células basais, em aves de companhia (Arnall, 1958; Reece, 1992; Tell et al., 1997). A ocorrência desta neoplasia é comumente relatada em cães e gatos, mas rara em outros animais domésticos (Yager e Scott, 1993; Hargis, 1995). A patogenia está diretamente relacionada com a exposição aos raios solares ultravioletas ou raio-X, mas o trauma também é considerado um fator importante na etiopatogenia do carcinoma de células basais (Ozyazgan e Kontas, 2004). Em aves estes traumas incluem agressões severas, infecções por poxvírus, queimaduras e lesão tecidual causada por vacinação (Noodleman e Pollack, 1986). Não há evidências concretas sobre a origem da lesão neste caso, no entanto, a localização na região medial da asa torna menos provável que tenha sido desencadeado pela ação de raios ultravioletas. A possibilidade de que esta lesão tenha origem traumática, desencadeada por condições inapropriadas da gaiola, não é rejeitada.

A célula basal é uma célula pouco diferenciada, e se divide continuamente dando origem às células das outras camadas da epiderme ou aos anexos cutâneos, inclusive folículo da pena (Tell, 1997). No presente caso, a lesão apresentou as mesmas características descritas por Schmidt e Queensberry (1997) que destacaram, em aves, lesões representadas por massas grandes e com áreas centrais de ulceração. Também houve similaridade com os achados de Tell et al. (1997) onde o carcinoma de células basais mostrou-se de consistência firme, arredondado, elevado, bem circunscrito, e localizado entre a derme e a epiderme, sendo geralmente solitário.

Tell et al. (1997) sugere que, em aves, os carcinomas de células basais podem apresentar características peculiares, tendo inclusive potencial para produzir metástases. No entanto, neste caso o paciente foi acompanhado e não apresentou alterações clínicas nos 13 meses que se seguiram à cirurgia, corroborando outras opiniões a respeito dessa neoplasia, classificada como maligna, com comportamento localmente agressivo e potencial baixo para produzir metástases e recidivas (Baker e Thomsett, 1990; Yager e Scott, 1993; Hargis, 1995; Scott et al. 1996). Os autores salientam, no entanto, que o número reduzido de relatos destas lesões em aves dificulta o esclarecimento do comportamento destas neoplasias.

O baixo número de relatos na literatura de carcinoma de células basais em aves não reflete necessariamente a incidência real desta patologia na população aviária. O estabelecimento de uma rotina de análise histopatológica em tumores de aves é essencial para o diagnóstico preciso da lesão e para auxiliar no esclarecimento da etiopatogenia desta e de outras neoplasias, contribuindo, desse modo, para a adoção de medidas profiláticas nas criações em cativeiro. 


\section{Referências}

ARNALL, L. Experiences with cage birds. Vet. Rec., v. 70, n. 6, p. 120128, 1958.

BAKER, J. R. A survey of causes of mortality in budgerigars (Melopsittacus undulatus). Vet. Rec., v. 106, n.1, p. 2-10, 1980.

BAKER, K. P.; THOMSETT, L. R. Neoplasia and Cysts In: Canine and Feline Dermatology. London: Blackwell Scientific Publications, 1990. p. 172-203.

HARGIS, A. M. Integumentary System In: CARLTON, W. W. (Ed.); Mc GAVIN, M. D. (Ed.) Thomson's Special Veterinary Pathology. St. Louis, Missouri: Mosby, 1995. p. 461-511.

LATIMER, K. S. Oncology In: RITCHIE, B. W. (Ed.), HARRISON, G. J. (Ed.), HARRISON, L. R. (Ed.). Avian Medicine: Principles and Applications. Florida: Wingers Publishing, 1994. p. 640-672.

MUNSON, L. Genetics: Inbreeding and Diseases in Captive Wild of Animal In: FOWLER, M.E. (Ed.). Zoo \& Wild Animal Medicine: Current Therapy 3. Colorado: W.B Saunders Company, 1993. p. 68-86.

NOODLEMAN, F.; POLLACK, S. V. Trauma as a possible etiologic factor in basal cell carcinoma. Dermatol. Surg. Oncol., v. 12, n.8, 841-845, 1986.
OZYAZGAN, I.; KONTAS, O. Previous injuries or scars as risk factors for the development of basal cell carcinoma. Scand J Plast Reconstr Surg Hand Surg., v. 38, n. 1, p. 11-15, 2004.

REECE, R. L. Observations en naturally occurring neoplasms in birds in the state of Victoria, Austrália. Avian Pathology, v. 21, p. 3-32, 1992. SCHMIDT, R. E.; QUESENBERRY, K. Neoplasic Diseases In: ALTMAN, R. B. (Ed.); CLUBB, S. L.; DORRESTEIN, G. M.; QUESENBERRY, K. Avian Medicine and Surgery. Philadelphia: W.B. Saunders Company, 1997. p. 590-603.

SCOTT, D. W.; MILLER, W. H.; GRIFFIN, C. E. Tumores Neoplásicos e Não-neoplásicos In: Dermatologia de pequenos animais. Philadelphia: Interlivros, 1996. p. 926-1054.

TELL, L. A.; Woods, L.; Mathews K. G. Basal Cell Carcinoma in a Bluefronted Amazon Parrot (Amazona aestiva). Avian Diseases, v. 41, n. 3, p. 755-759, 1997.

YAGER, J.A.; SCOTT, D.W. The Skin and Appendages In: JUBB, K.V.F.; KENNEDY, P.C.; PALMER, N. Pathology of Domestic Animals. California: Academic Press, 1993. p. 531-738. 